\title{
Communication and Essentialism: Grounding the Shared Reality of a Social Category
}

\author{
Yoshihisa Kashima \\ The University of Melbourne \\ Emiko S. Kashima \\ La Trobe University \\ Paul Bain \\ Murdoch University \\ Anthony Lyons \\ The University of Melbourne \\ R Scott Tindale \\ Loyola University Chicago, rtindal@luc.edu
}

See next page for additional authors

Follow this and additional works at: https://ecommons.luc.edu/psychology_facpubs

Part of the Psychology Commons

\section{Recommended Citation}

Yoshihisa Kashima, Emiko S. Kashima, Paul Bain, Anthony Lyons, R. Scott Tindale, Garry Robins, Cedric Vears, and Jennifer Whelan (2010). Communication and Essentialism: Grounding the Shared Reality of a Social Category. Social Cognition: Vol. 28, Special Issue: Shared Reality, pp. 306-328.

This Article is brought to you for free and open access by the Faculty Publications and Other Works by Department at Loyola eCommons. It has been accepted for inclusion in Psychology: Faculty Publications and Other Works by an authorized administrator of Loyola eCommons. For more information, please contact ecommons@luc.edu. cc) (i) $\Theta$

This work is licensed under a Creative Commons Attribution-Noncommercial-No Derivative Works 3.0 License. (c) Guilford Press, 2010. 
Authors

Yoshihisa Kashima, Emiko S. Kashima, Paul Bain, Anthony Lyons, R Scott Tindale, Gary Robins, Cedric Vears, and Jennifer Whelan 


\title{
COMMUNICATION AND ESSENTIALISM: GROUNDING THE SHARED REALITY OF A SOCIAL CATEGORY
}

\author{
Yoshihisa Kashima \\ The University of Melbourne \\ Emiko S. Kashima \\ La Trobe University \\ Paul Bain \\ Murdoch University \\ Anthony Lyons \\ The University of Melbourne \\ R. Scott Tindale \\ Loyola University of Chicago \\ Garry Robins, Cedric Vears, and Jennifer Whelan \\ The University of Melbourne
}

\begin{abstract}
Essentialism is an ontological belief that there exists an underlying essence to a category. This article advances and tests in three studies the hypothesis that communication about a social category, and expected or actual mutual validation, promotes essentialism about a social category. In Study 1, people who wrote communications about a social category to their ingroup audiences essentialized it more strongly than those who simply memorized about it. In Study 2, communicators whose messages about a novel social category were more elaborately discussed with a confederate showed a stronger tendency to essentialize it. In Study 3, communicators who elaborately talked about a social category with a naive conversant also essentialized the social category. A meta-analysis of the results supported the hypothesis that communication promotes essentialism. Although essentialism has been discussed primarily in perceptual and cognitive domains, the role of social processes as its antecedent deserves greater attention.
\end{abstract}

The research reported in this article was supported by a grant from the Australian Research Council. We thank Liliana Braumberger and Kate O'Halloran for serving as confederates in Study 2. We are also grateful for Dave Hamilton, Mike Hogg, and Gerald Echterhoff for their critical comments on an earlier version of this article.

Correspondence concerning this article should be addressed to Yoshihisa Kashima, Department of Psychology, The University of Melbourne, Parkville, Victoria 3010, Australia. E-mail: ykashima@ unimelb.edu.au. 
Social scientists have taken for granted the observation that humans construct social reality through symbolically mediated social interaction. Large scale social institutions such as nation states, financial systems, and even universities are undoubtedly human constructions that define social realities, which in turn shape human social action (e.g., Durkheim, 1982; Giddens, 1993). Social interactions in small groups, too, generate social reality that is largely emergent in the particular situation (e.g., Asch, 1952; Festinger, 1950; Sherif, 1936). However, until a recent return of interest in the social basis of cognition, this critical observation had lain dormant in the background of social psychological theorizing, despite some notable exceptions (e.g., Moscovici, 1976; Rommetveit, 1974). While philosophers (e.g., Searle, 1995) are debating the ontological structure of social reality, there is a critical question of how we come to have a psychological sense of social reality, which Higgins and his colleagues called shared reality (e.g., Hardin \& Higgins, 1996; Higgins, 1992), and what may be its social psychological consequences.

All the more significant for social psychology is the shared reality of a social category, or a large aggregate of individuals such as gender-, ethnicity-, and nationality-based groups. A social category is a distinct type of social group (Lickel et al., 2000); however, not all social categories are equally psychologically real. As Allport (1954) noted, some social categories have "primary potency" and "act like shrieking sirens, deafening us to all finer discriminations that we might otherwise perceive" (p. 179). These are psychologically real social categories. With Rothbart and Taylor (1992), we suggest that psychologically real social categories may be essentialized, that is, seen to possess an immutable underlying essence. In this article, we consider interpersonal communication as a source of the psychological sense of social reality. As Hardin and Higgins (1996) put it,

in the absence of social verification, experience is transitory, random, and ephemeral ... But once recognized by others and shared in an on-going, dynamic process of social verification ... experience is no longer subjective; instead, it achieves the phenomenological status of objective reality. That is, experience is established as valid and reliable to the extent that it is shared with others" (p. 28).

In particular, as Kashima (2004) suggested, under some circumstances, a communicator's act of speaking about a social category and establishing a mutual understanding about it with an audience--the process that Clark (1996; see Kashima, Klein, \& Clark, 2007) called grounding--may be sufficient for the communicator to establish what Higgins and his colleagues called a shared reality, and to essentialize the social category. We explicate this hypothesis below, and three studies are reported in its support.

\section{COMMUNICATION AND ESSENTIALISM}

What would happen when people learn about a novel social category? One of the consequences, largely neglected in social psychology, is for them to talk about it. Let us call the person who has the information about the category, sender, and the other who is ignorant of it and receives the sender's communication, receiver. Under this circumstance, how would their conversation proceed? Clark's (1996) grounding model gives a clear guidance. The sender begins a phase of communi- 
cation by presenting an utterance that contains some propositional representations about the social category: Group X is like P, where P stands for some properties of the group. In order to complete the communication, the receiver is obliged to indicate his or her understanding of the utterance (i.e., acceptance) by providing the sender with verbal or nonverbal evidence that he or she has understood it appropriately. Evidence could take various forms (e.g., Bavelas, Coates, \& Johnson, 2000; Clark, 1996), from a simple acknowledgment such as "OK" or "Oh, yeah," to a more elaborate paraphrasing or probing questions, such as "So, group X is like $\mathrm{P}$, and they do things like p1, p2, and p3, huh?" When the sender gains sufficient confidence that the receiver has understood his or her impression about the social category, or the group impression is grounded between the communicators well enough, this phase of the communication ends.

The grounding of the sender's impression by the receiver may establish shared reality in the sense Hardin and Higgins (1996) described it. Because the sender is the only person who has the information, the receiver is unlikely or unable to disagree with the sender's impression. In the absence of a disagreement, the receiver's understanding of the sender's impression may be seen by the sender as evidence that the receiver has also agreed with the sender's impression. Note that Echterhoff, Higgins, and Groll's (2005) findings imply that people infer from a successful referential communication the agreement about the impression unless there is evidence to suggest otherwise (we will return to this point later). Underlying this process is the sender's epistemic motivation to verify his or her knowledge intersubjectively by establishing shared reality (Echterhoff, Higgins, Kopietz, \& Groll, 2008). If the receiver's acceptance of the sender's presentation is elaborate, its effect on the sender is likely to be greater than when the receiver accepts it with a minimal acknowledgment. This is because more elaborate grounding would give stronger evidence of intersubjective verification, and help the sender gain greater confidence in the establishment of a shared reality with the receiver.

We contend that when the sender's impressions about a social category are more extensively grounded and intersubjectively validated, the more essentialized the sender's perceptions of the social category may become. Essentialism is a naive ontological belief that there exists an underlying hidden reality, or an immutable essence, beneath the surface appearance of category exemplars (e.g., Gelman, 2004; Medin \& Ortony, 1989). In line with Medin and Ortony's thinking, we suggest that people have a cognitive schema about a category, which we call the essenceappearance schema. In this schema, appearances are observable characteristics of the exemplars of a category; an essence is that which causes, generates, and gives rise to the appearances. When this schema is used to understand a category, the category is essentialized. An essence is usually unobservable, and therefore people often do not know what it is. It is best regarded as a "placeholder" (Medin \& Ortony, 1989). People only have to assume that there exists something which causes the appearances. Critically, the essence must be immutable. If a category can be changed by human activities, it is an artifact, and it does not have a reality independent of human action. Once a category is essentialized, and its essence is regarded as unchangeable, human efforts cannot do anything about it, and it lies in the realm that cannot be touched by human intervention.

The present hypothesis--communication promotes essentialism--has important boundary conditions. First of all, the sender should have some ambiguous information about a social category, but the receiver should have no information about 
the social category. Second, the sender should attribute sufficient epistemic credibility to the receiver in order for the latter to be treated as a partner for intersubjective verification. When the sender has an epistemic authority about ambiguous information and the receiver is sufficiently credible, the sender would feel an epistemic need to verify his or her impression intersubjectively, assume that the receiver's understanding implies his or her endorsement and verification, and trust the receiver's endorsement as sufficient evidence for the veridicality of the grounded information. Thus, excluded from the scope of the present hypothesis are the conditions in which (1) the sender's information is unambiguous, or (2) both the sender and receiver have some information about a social category. In (1), the sender would feel no need for intersubjective verification, and therefore it falls outside the scope of shared reality theory. In (2), the grounding of impressions is unlikely to be sufficient because the receiver is more likely to question the sender's impression or to express a disagreement, thus failing to establish a shared reality. In what follows, we elaborate on the present hypothesis by considering the measurement of essentialism and reviewing the existing literature on communication and group perception.

\section{Measuring Essentialism}

We use the following two aspects as indices of essentialization of a social category: (1) attribution of a trait disposition to the social category, and (2) belief that this disposition is unalterable or immutable. Theoretical justification for this decision is presented below.

Dispositional Attribution. When people apply the essence-appearance schema to a social category, they may attribute a disposition to the social group. Indeed, as Yzerbyt, Rogier, and Fiske (1998) showed, when a collection of individuals is seen to belong to a real social category (a university), people attributed dispositions more strongly to the target group than when they were seen to be a mere aggregate of individuals. Note that a stronger dispositional attribution can be measured as an extreme rating of a social category on a trait dimension, an oft-used measure of social stereotypes. Park and Judd (1990) showed that those who attribute a trait disposition strongly to a group tend to see the disposition to be widely shared within the group, and this perceived prevalence of the disposition is highly related to perceived consistency of group behavior (Kashima et al., 2005). If a member of a group is observed to have behaved in a certain way, another member is likely to behave in a similar manner. Essentialism in this sense may be understood as an aspect of perceived entitativity (Campbell, 1958), the perceived "degree of having the nature of an entity or having real existence" (p. 17), as some have argued (e.g., Ip, Chiu, \& Wan, 2006; Kashima et al., 2005; see Yzerbyt, Judd, \& Corneille, 2004, for a variety of views). One strand of research has used this concept to measure (e.g., Brewer, Weber, \& Carini, 1995) and to manipulate (e.g., Dasgupta, Banaji, \& Abelson, 1999) perceived entitativity. Perceived consistency also mediates group impression formation (e.g., Hamilton \& Sherman, 1996).

Immutability Belief. The second aspect of essentialism--belief that the underlying essence of a social category is believed to be immutable--is particularly important. We believe that one psychological symptom of some socially constructed object to be treated as an aspect of social reality is that the object is believed to be un- 
alterable by human intervention; that is, people believe that the object cannot be changed. Dweck's (1999) notion of entity theory aptly captures this aspect of essentialism. According to Dweck and her colleagues (1999; Dweck, Chiu, \& Hong, 1995), there are two general implicit theories about human nature. Entity theory holds that various attributes of a person are fixed and cannot be changed by effort, whereas incremental theory holds that attributes are malleable and can be altered by self-development and cultivation. Bastian and Haslam (2006) showed that entity theory was one of the central aspects of the broader syndrome of essentialism. Linking the immutability aspect of essentialism to its dispositionism aspect, Chiu, Hong, and Dweck (1999) showed that, from an observation of an individual target's behavior, entity theorists are more likely than incremental theorists to infer the target's underlying disposition, to generalize the observation to another context, and to make an extreme evaluation of the target. Levy, Stroessner, and Dweck (1998) extended this work to social categories, showing that those who believe that a social category has an unchangeable essence tend to hold stronger stereotypes.

It is often said that an essentialized social category is not only immutable, but should also be biologically based. However, we contend that not all essences of essentialized social categories may be biological. Take a social category of Muslims for example. This category may be essentialized if people regard its essence--belief in Allah and way of living according to the Koran--to be an unchangeable essence of their being, and it gives rise to its observable behavioral characteristics. Belief in Allah does not have to be biologically based; all that is required in our definition of essentialism is that people believe it is unchangeable. In this sense, our definition entails the biologically based essentialism as its subset, but is broader than the latter because it can be used to characterize social categories that are thought to possess a nongenetic essence.

\section{Communicating About a Social Category}

We hypothesized that when a social category is well grounded and a shared reality is established, the sender's perceptions of the social category are essentialized, understood in terms of both (1) stronger dispositional attribution, and (2) greater perceived immutability of the disposition. Whereas no evidence exists for (2), the existing literature is consistent with (1). In Zajonc's (1960) cognitive tuning work, those who anticipated to communicate about a target person were shown to construct a more coherent impression about the target than those who expected to receive a communication. Subsequent research showed that senders were more likely than receivers to make trait inferences spontaneously (e.g., Hoffmann, Mischel, \& Baer, 1984) and make stronger dispositional attributions to the target person (e.g., Harvey, Harkins, \& Kagehiro, 1976; for a review, see Guerin \& Innes, 1989). In this article, we will call polarization the tendency to make more extreme dispositional judgments about a target when strong dispositional attributions are made on a bipolar dimension anchored by two contrasted traits (e.g., kind vs. unkind). In a related vein, Higgins and Rholes (1978) gave their participants ambivalent information about a target individual, and told them to communicate about the target to an audience whose attitude toward the target was either positive or negative, so that the audience can identify the target. The message showed an audience tuning: the participants described the target positively (negatively) for 
the audience who liked (disliked) the target, evaluated the target accordingly on personality trait terms (i.e., stronger dispositional attribution), and recalled the information congruent with the evaluation. Moreover, impressions became even stronger after a delay. This has been called a "saying is believing (SIB)" effect. In contrast, when participants did not communicate about the target, they did not show any SIB effect. Thus, communications polarized impression judgments relative to the no communication condition.

Echterhoff et al.'s $(2005,2008)$ findings suggest that the SIB effect is largely due to the communicators' expectation and belief that they successfully grounded their shared reality of the target with the audience. Using recall, the SIB effect was obtained when the communicator was led to believe that the audience was able to understand who the target was or that the audience was an ingroup member, who he or she thought can be trusted as a source of valid information. Thus, beliefs or expectations of successful grounding played an important role in the emergence of a SIB. Zajonc's (1960) Experiment 2 corroborates this point: he found a stronger cognitive tuning effect when the message senders believed that their audience was likely to agree with them than when they thought the audience would disagree with their message. Taken together, the literature suggests that when the message senders expected their audience would corroborate their impression of a target individual, the senders' impressions were more coherent and polarized.

Extending the communication effects on person perceptions to group perceptions, Thompson, Judd, and Park (2000) reported that when two people with firsthand information about a group (senders) and two others who had no information (receivers) discussed about the target group that was described by a mixture of stereotypical and counter-stereotypical information, both the senders' and receivers' impressions about the group were more polarized than when they had no discussion. Within the "saying is believing" experimental paradigm, Haussmann, Levine, and Higgins (2008) also showed that the SIB effect was obtained for a group target as well. Brauer, Judd, and Jacquelin's (2001) findings suggest that this polarization effect is likely due to the grounding of the stereotypical information, and its intersubjective validation. When everyone in a three-person discussion group had more stereotypical than counter-stereotypical information, their impressions after the discussion were more polarized than when one of the three members had more counter-stereotypical than stereotypical information (the other two had more stereotypical than counter-stereotypical information). Apparently, the dissenting voice of the person who had more counter-stereotypical information disrupted the grounding of the stereotypical information, thus preventing the impressions from polarizing.

\section{Present Research}

We tested the hypotheses that communication about a group strengthens the sender's attribution of trait-like dispositions to the group, and immutability perceptions of the group. In Study 1, we examined the effect of written communication to ingroup members about impressions about a new outgroup. Participants received behavioral information about members of a social category (i.e., an unnamed residential college at the university), and asked to communicate or to memorize them. In the communication condition, they wrote letters describing the group. Group 
impressions in the communication and memory conditions were compared. Using similar stimuli, Study 2 examined the effect of grounding activities generated by the receiver on the sender's group impressions by manipulating the receiver's responses. In Study 3, we allowed a sender and a receiver to interact freely face-toface, and examined the effects of naturally occurring grounding activities on the sender's and receiver's group impressions.

\section{STUDY 1}

This study examined the effect of senders' communication on their tendency to essentialize. Participants were given mildly positive or negative information about the target group, and told to communicate about it to their friends and relatives, arguably the people with whom they would expect to be able to ground their shared reality. The memory condition served as a control condition. Participants were then asked to make attributions of trait dispositions and judgments of immutability of the dispositions. It was hypothesized that the expectation of successfully grounding information about a novel group would be sufficient to essentialize the communicator's group impression. Attributions of dispositions that correspond to the stimulus information would be stronger (and therefore trait attributions be more polarized) and the dispositions would be more strongly believed to be immutable in the communication condition than in the memory condition.

\section{METHOD}

\section{Participants and Design}

Ninety-two undergraduate students (30 men, 62 women) at a university in Melbourne, Australia, were recruited for participation in this experiment. They were paid AUD5 for one hour. The experiment was two-way factorial. One factor was the instructions, communication versus memory. The other factor was the stimulus condition. Friendly behaviors were more prevalent in one condition, and hostile behaviors were more prevalent in the other condition (friendly vs hostile).

\section{Stimuli}

The stimuli were 20 behavioral episodes purportedly performed by individual members of a group on campus. The behaviors were selected from a pool of items pretested on 100 participants to determine the extent to which they are hostile or friendly on a 9-point scale ( $1=$ hostile, $9=$ friendly). The mean ratings were used as estimates of the scale values of those items. The number of episodes for the friendly condition were 2 (3-4, namely, scale values between 3 and 4), 4 (4-5), 8 (5-6), 4 (6-7), and 2 (7-8). The behaviors for the hostile condition were 2 (2-3), 4 (3-4), $8(4-5), 4(5-6)$, and 2 (6-7). Therefore these items roughly formed a symmetric distribution on the bipolar dimension with the mean slightly on the friendly side in the friendly condition, and vice versa. 


\section{Procedure}

Upon arrival, participants were told that the purpose of the experiment was to examine the process by which people deal with information about other people's behaviors. Half of the participants were told that their task is to memorize the information presented about a group of people (memory condition), and the other half was told to read the information so that they can communicate what they have learned about the group (communication condition). The stimuli were then presented in a booklet with one behavioral episode printed on each page. The participants were given 8 seconds to read each page.

In the communication condition, the participants were asked to write three short notes about the group to three different people: an older relative, a high school friend, and a university friend. They were given 2 minutes to write each note. In the meantime in the memory condition, the participants were given a distracter task of drawing the floor plan of their house. Immediately afterwards, the participants were then given a questionnaire containing dependent variables.

The participants were first asked to report their impressions of the group on six trait dimensions (5-point scale: 5 = extremely descriptive, $1=$ not at all descriptive). Three traits were consistent with friendliness (friendly, warm, outgoing) and the other three were consistent with hostility (hostile, cold, aggressive). The traits were presented in a random order.

Next, two other tasks were presented in random orders. One was a consistency judgment in which the participants judged the likelihood that another member of the group would have each of the personality traits as in the impression judgment task. The other was a percentage estimation task in which the participants estimated the percentage of the members of the group who would have each personality trait. The same traits were used and the response scale varied from 0 to 100 .

Finally, the participants responded to three items to measure people's implicit theory of personality (Chiu et al., 1997). Although the original items asked about the immutability of people's disposition in general, the present version was reworded to tap the respondent's perceived immutability of the particular group. The items were: "It is unlikely that the core disposition of this group can be altered though some things may be modified," "This group has its basic and ingrained dispositions, and you really can't do much to change them," and "Some events may change superficial things about the group, but the fundamental nature of this group is something that cannot be changed much." The participants used a 5-point Likert scale $(1=$ disagree, 5 = agree $)$.

\section{RESULTS}

Because factor analyses of the friendly and hostile trait attributions formed two independent factors the judgments on friendly traits and the judgments on hostile traits were averaged separately. Cronbach's $\alpha$ s were .78 and .88 , for friendliness and hostility attributions. Similarly, percentage estimates and generalizability judgments were aggregated to compute perceived consistency measures: friendliness and hostility judgments were averaged separately. Cronbach's $\alpha$ s were .88 and .95 for friendly and hostile consistency judgments. The items for immutability 
TABLE 1. Effects of Instructions on Trait Dispositional Attribution and Perceived Consistency on Stimulus Consistent and Non-Consistent Traits, and Immutability Belief, and Their Relevant Means in the Memory and Communication Conditions in Study 1

\begin{tabular}{lcccc}
\hline Measurement & Memory & Comm. & $\mathbf{F ( 1 , 8 8 )}$ & $\eta_{p}{ }^{2}$ \\
\hline Trait Dispositional Attribution & & & & \\
$\quad$ Consistent Traits & 3.3 & 3.8 & $8.14^{* *}$ & .09 \\
$\quad$ Other Traits & 2.2 & 2.3 & 0.34 & .00 \\
Perceived Consistency & & & & \\
$\quad$ Consistent Traits & 49.5 & 61.1 & $6.74^{*}$ & .07 \\
$\quad$ Other Traits & 28.0 & 29.8 & 0.30 & .00 \\
Immutability Belief & 3.0 & 3.4 & $5.28^{*}$ & .06 \\
\hline Note. ${ }^{* *} p<.01,{ }^{*} p<.05$ & & & &
\end{tabular}

belief items were averaged to form an immutability belief index (Cronbach's $\alpha=$ .67).

To examine the effect of communication, a two-way analysis of variance (ANOVA) was conducted on dispositional attributions of the consistent traits (i.e., friendliness attributions in the friendly stimulus condition, and vice versa). One factor was prevalent behavior (friendly vs. hostile) and the other factor was instruction (communication vs. memory). Only the main effect of instruction was significant, suggesting that the effect of communication did not depend on the valence of the stimuli. The results are summarized in Table 1. Consistent with expectation, communicating about the target group polarized the judgments on traits that are consistent with the overall impression of the group.

Interestingly, a comparable analysis on trait judgments about the nonconsistent traits (i.e., friendly traits in the hostile behavior condition, and vice versa) showed that the communication did not polarize the attribution of dispositions that are not closely related to the stimulus information. There was no significant effect of instruction (see Table 1). However, trait attributions were slightly higher in the hostile $(M=2.5)$ than in the friendly condition $(M=2.1), F(1,88)=5.38, p<.05, \eta_{p}{ }^{2}$ $=.06$. Presumably, people were more willing to attribute friendly than hostile traits even when the overall impression was negative.

Likewise, comparable ANOVAs were conducted for the perceived consistency on the consistent and nonconsistent traits. Again, the instruction main effect was significant for the consistent traits (Table 1): participants perceived a higher degree of consistency among the group members' behaviors after they had communicated about the group than when they had simply recalled their observations. With regard to the nonconsistent traits, only a prevalent behavior main effect was significant. Mirroring the trait judgments, perceived consistency among group members was greater in the hostile condition $(M=38.7)$ than in the friendly condition $(M=$ 19.0), $F(1,88)=35.94, p<.001, \eta_{p}^{2}=.29$.

Finally, immutability belief was subjected to an ANOVA. The instruction main effect was the only significant effect (Table 1): communicating about the target group strengthened the belief that the group disposition is unalterable. 


\section{DISCUSSION}

As expected, communicating about a target group, relative to memorizing about it, essentialized the sender's group impressions by polarizing the attribution of trait dispositions that are consistent with the overall impression of the group, and strengthening the immutability belief about the group. Overall, communication may help essentialize a social category. This is analogous to, but also extends, Echterhoff et al.'s (2005) finding that a message production for an ingroup member was sufficient to generate a SIB effect. Echterhoff et al.'s finding was concerned about an effect of message production on recall; in this study, we showed that message productions for ingroup members were sufficient not only to polarize the group impression, but also to strengthen the immutability belief about the group's essence.

It is interesting to note that perceived consistency also showed a pattern comparable to dispositional attribution. The attribution of trait dispositions to a group and consistency judgments were so highly correlated (between .64 and .80) that they are likely to be measuring the same underlying construct. Indeed, our perceived consistency measure is very similar to one type of perceived homogeneity measure used by Park and Judd (1990; percentage estimation task), in which these measures and trait attribution measures loaded on the same underlying latent variable. We will drop the perceived consistency measure from the next studies.

Interestingly, the communication did not affect the attribution of trait dispositions that are not consistent with the overall impression of the group. The perceived consistency again showed a comparable pattern. Thus, it is not that communication strengthens any beliefs, but its effects are selective and localized to the judgments relevant to the stimulus information. Presumably, when people communicate about a target group, they attempt to present a coherent picture about it; in so doing, the information that is consistent with the overall impression may be emphasized more, but the other information may not be affected. It is noteworthy that, although the original stimuli were pilot tested in terms of the bipolar dimension of friendliness versus hostility, this bipolar dimension may be better understood as two related unipolar dimensions. A group that is not friendly is not necessarily hostile, but may be simply neutral; a group that is not hostile is not always friendly. In order to avoid this complication, different stimuli were used to extend the generality of the findings.

\section{STUDY 2}

Study 1 showed that a sender's message production may be sufficient to essentialize the sender's views about the social category even in the absence of the receiver's response. In this second study, we examined the potential effect of the receiver's grounding by systematically manipulating the receiver's grounding behavior. In particular, we trained confederates to interact with senders differently: in one condition, the receivers were trained to accept the sender's message only minimally by nodding or uttering a brief sentence (minimal grounding) or more extensively by paraphrasing or asking relevant questions (elaborate grounding). We also measured grounding activities in this study. Although duration of time 
that people spent talking about relevant information has been measured in previous studies on group discussion and stereotype formation, grounding activities have not been directly measured.

\section{METHOD}

\section{Participants and Design}

Forty undergraduate students at a university in Melbourne, Australia participated in the experiment (17 men, 23 women). They were all native speakers of English or had lived in Australia more than 15 years. Each participant was paired with one of two female confederates.

There were two experimental conditions (minimal vs. elaborate grounding) in which a female confederate posed as a participant. In both conditions, the confederate started the conversation by asking the participant for information about the club members. However, in the minimal grounding condition, the confederate gave only brief responses (e.g., "OK," "um-hum," "right"), nonverbal behaviors (e.g., nods and gestures), and asked brief, nonspecific questions to maintain the conversational flow where required (e.g., "So can you remember anything else?"). In the elaborate grounding condition, the confederate responded with more elaborate responses by paraphrasing the sender's impressions (e.g., "OK, so the club members sound really organized then"), and asked more specific questions (e.g., "So do you think they were nice people, or nasty?), in addition to nonverbal behaviors.

Within each grounding condition, either positive or negative behaviors of members of an unidentified university club were presented. Thirty-six behaviors were selected from a pool of behaviors that had been rated by separate 46 participants on kindness and organization $(1=$ unkind to $9=$ kind; $1=$ disorganized to $9=$ organized). The means were used to estimate their scale values. For the positive stimulus set, 8 behaviors were selected whose scale values were between 5 and 6 on both kindness and organization. Then, for each dimension (e.g., kindness), we selected 3 (8-7), 5 (7-6), 4 (5-4), and 2 (4-3) behaviors. These latter behaviors' scale values were in the neutral range (i.e., between 4 and 6) on the other dimension (e.g., organization). Likewise, for the negative stimulus set, 8 behaviors were selected whose scale values were between 4 and 5 on both dimensions. Again, for each dimension, we selected 3 (2-3), 5 (3-4), 4 (5-6), and 2 (6-7) behaviors. These latter behaviors were neutral on the other dimension (between 4 and 6).

The design was a grounding condition (minimal vs. elaborate) $x$ prevalent behavior (positive vs. negative) factorial.

\section{Procedure}

Sessions took place in a small interview room equipped with a video camera. Each participant was introduced to a confederate as another naive participant, who was said to be the participant's conversation partner. The experimenter then asked the confederate to wait outside while the participant completed a task. The participant read an instruction sheet informing them that they would be reading some information about members of a university club, so that he or she can "communicate 
what you have learned about the group to your communication partner." One half of the participants read the positive set, whereas the other half read the negative set. Each behavior was printed on one card, and they were given 8 seconds to read each card. The order of the cards was randomized for each session by shuffling them. Once the participant had finished reading the stimuli, the confederate was returned to the room. Both the participant and confederate were given a second instruction sheet explaining the conversation task. They were told that a conversation would continue for 3 minutes, and that the receiver was to start the conversation by asking questions about the target group. The experimenter left the room, and returned after 3 minutes. Even if the conversation was continuing, it was terminated at that point. At the conclusion of the conversation, both participant and confederate completed the questionnaire rating the target group on four trait dimensions (kind, unkind, organized, and disorganized) on a 5-point scale ( $1=$ not at all, $5=$ very) and in terms of the three immutability belief items ( $1=$ disagree, 5 $=$ agree). The participant was fully debriefed as to the confederate's identity at the conclusion of the session.

\section{RESULTS AND DISCUSSION}

\section{Conversational Data}

The videotaped conversations were transcribed. Each conversation was first broken into conversational units based on grounding activities. In its simplest form, a conversational unit consisted of the presentation of some information by one participant, and the acceptance by the confederate. In more complex examples, a conversational unit might contain two or three presentations and acceptances by the participant and confederate to establish mutual understanding of the topic. Nonetheless, to the extent that one segment of a conversation was concerned about one topic, it was coded as a conversational unit. Two coders undertook this analysis independently first, and then they discussed to resolve their disagreements, so that the subsequent coding could be conducted further.

Each conversational unit was coded as a whole at three levels of grounding: assumed, minimal, or extended. A conversational unit in which the presentation of relevant information was met by neither verbal nor nonverbal responses that indicated acceptance of the information was coded as assumed grounding. The past research in group discussions would have coded such instances as the presence of relevant information in discussion; following this convention, we regarded this as the transmission of some information in the conversation. Minimal grounding was indicated by a nonverbal response by a conversant or by a brief verbal response that indicated the conversant's understanding (e.g., "OK," "Right," "Uh-hm"). Extended grounding was indicated by more elaborate and detailed responses (e.g., "OK, so they had pretty busy lifestyles then") or by more specific questions (e.g., "Did you get the impression they were nice people?"). Each conversational unit contained one or more presentations about relevant information: each presentation was coded in terms of whether it implied kind, unkind, organized or disorganized impressions. The inter-rater reliability (Cohen's $\kappa$ ) between two independent coders was satisfactory for grounding $(\kappa=.74)$ and for the classification of presentations $(\kappa=.76)$. Disagreements were resolved by discussion. 
Based on the agreed coding, grounding score was computed for each conversational unit using the following formula: $G L^{*} A b s[N(k)-N(u)+N(o)-N(d)] /$ $[N(\mathrm{k})+N(\mathrm{u})+N(\mathrm{o})+N(\mathrm{~d})]$, where GL indicates the level of grounding achieved for the conversational unit (Assumed Grounding = 1; Minimal Grounding = 2; Elaborate Grounding $=3), \mathrm{N}($ ) represents the number of pieces of information, kind $=\mathrm{k}$, unkind $=\mathrm{u}$, organized $=\mathrm{o}$, or disorganized $=\mathrm{d}$, and Abs[] indicates the absolute value of the number within the square brackets. When there was no relevant information in a given conversational unit (i.e., $N(\mathrm{k})+N(\mathrm{u})+N(\mathrm{o})+N(\mathrm{~d})=0$ ), this score was set at 0 . The score was then summed across all conversational units.

This index is based on the assumption that people would aggregate information for each conversational unit, and the manner of aggregation followed the weighted averaging model (e.g., Anderson, 1981; Kashima, Woolcock, \& Kashima, 2000) where a positive piece of information was scaled as +1 and a negative piece scaled as -1 . Because the main dependent variable was extremity of the judgments on kindness and organization, its absolute value was multiplied by the grounding level, so that the more elaborate is the type of grounding, the higher is the grounding score. We then simply aggregated the scores of conversational units by summing them.

\section{Judgment Data}

The absolute value of the difference between the rating of kindness and the rating of unkindness was computed to index the dispositional attribution of kindness; the absolute value of the difference between the rating of organization and that of disorganization was used as a measure of dispositional attribution of organization. Immutability belief was computed by averaging the three items and the reliability was reasonable $(\alpha=.67)$.

\section{Preliminary Analyses}

The extremity, immutability belief, and grounding measures were compared between the two confederates. No differences were detected. Confederate was not included in further analyses. Second, the effectiveness of the grounding manipulation was checked by subjecting the grounding measure to an ANOVA with prevalent behavior (positive vs. negative) and condition (elaborate vs. minimal grounding) as between-subjects factors. As expected, condition had the only significant effect, $F(1,36)=22.88, \eta_{p}{ }^{2}=.389, p<.001$. Grounding activities were more elaborate in the elaborate grounding condition $(M=4.92)$ than in the minimal grounding condition $(M=2.03)$.

\section{Dispositional Attribution and Immutability Belief}

Dispositional attributions of kindness and organization were analyzed by a mixeddesign ANOVA with prevalent behavior and condition as between-subjects factors and dimension (kindness vs. organization) as within-subjects factor. There was a 
TABLE 2. Correlations of Grounding with Extremity of Kindness and Organization Judgments and Immutability Belief in Studies 2 and 3

\begin{tabular}{lcccc}
\hline & Average Extremity & Kindness & Organization & Immutability Belief \\
\hline $\begin{array}{l}\text { Study } 2 \\
\quad\end{array}$ & $.44^{* *}$ & $.25+$ & $.43^{* *}$ & .21 \\
$\quad$ Sender & & & & \\
Study 3 & $.63^{* *}$ & .25 & $.64^{* *}$ & $.54^{*}$ \\
$\quad$ Sender & $.53^{* *}$ & $.45^{*}$ & $.38+$ & -.06 \\
$\quad$ Receiver & &
\end{tabular}

Note. ${ }^{* *} p<.01,{ }^{*} p<.05,+p=.06$, one-tailed

marginally significant condition effect, $F(1,36)=2.84, \eta_{p}{ }^{2}=.073, p=.10$, where the mean extremity was somewhat greater in the elaborate grounding condition $(M=$ $1.04)$ than in the minimal grounding condition $(M=.80)$. However, this effect was qualified by dimension, Wilks's $\Lambda=.88, F(1,36)=5.10, \eta_{p}{ }^{2}=.12, p=.03$. The attribution of organization was clearly greater in the elaborate grounding condition than in the minimal grounding condition $\left(M_{\text {elaborate }}=1.23, M_{\text {minimal }}=.75\right)$; however, extremity on kindness did not differ between the conditions $\left(M_{\text {elaborate }}=.85, M_{\text {minimal }}\right.$ $=.85$ ).

To examine whether grounding mediates the condition $x$ dimension interaction effect, an ANCOVA was conducted with the same three factors and grounding as a covariate. First of all, as expected, grounding had a significant main effect, $F(1$, $35)=5.25, \eta_{p}{ }^{2}=.131, p=.028$. This shows that the mediator has a direct relationship with the criterion. Second, the significant condition $x$ dimension interaction in the previous ANOVA became nonsignificant, Wilks's $\Lambda=.918, F(1,35)=3.14, \eta_{p}{ }^{2}$ $=.082, p=.085$, providing some evidence for mediation by measured grounding (Baron \& Kenny, 1986). The main effect of condition was not significant, $F(1,35)=$ $.001, \eta_{p}^{2}=.00, p=.971$.

To further examine the relationship between grounding and dispositional attribution, we computed the correlations of grounding with average attribution (averaged across kindness and organization), as well as attributions of kindness and of organization separately (Table 2). The correlations were generally significant except that the correlation involving attribution of kindness was only marginal ( $p$ $=.057)$.

Immutability belief was analyzed by an ANOVA with stimulus and condition as between-subjects factors. The predicted condition effect was not significant, $F(1$, 36) $=.79, \eta_{p}^{2}=.021, p=.38$. The correlation between grounding and immutability belief was not significant though in the expected direction (Table 2).

The manipulated grounding had an expected effect on dispositional attribution of organization; however, its effect was only marginal for kindness. Furthermore, the nature of the elaborate grounding condition was such that it basically invited the sender to make trait dispositional inferences. It is not too surprising that elaborate grounding resulted in a greater polarization. In addition, the manipulated grounding failed to produce a statistically significant effect on immutability belief. Although the results were generally encouraging, the contrived nature of the staged conversation may have produced weak effects. We examined the grounding in conversations between naive participants in Study 3. 


\section{STUDY 3}

In Study 3, we examined the effects of grounding on essentialism in free face-toface conversations involving naive participants. We expected that the more elaborate their grounding activities, the more essentialized their impressions would be. However, senders and receivers may respond differently to grounding activities. Note that our reasoning that senders would regard receivers' comprehension (i.e., grounding) as indicative of the latter's tacit agreement does not have to extend to receivers. When the sender's impression is grounded, he or she may feel that a shared reality is established, but the receiver may not. In line with this, Brauer, Judd, and Gliner's (1995) findings suggest that grounding may affect the senders more than the receivers. In their study, participants had a group discussion about attitudinal issues, and the effects of their expressing their own attitudes and hearing others' opinions were examined on their resultant attitudes. In two studies, expression of one's attitudes had a consistently positive effect on one's final attitudes; however, hearing others' opinions had little effect. Although this research is concerned with attitudes, and not about dispositional attributions, it suggests that senders' own expressions affected their own attitudes, but not receivers'.

Nevertheless, Thompson et al.'s (2000) Experiment 1 suggests that communication may affect receivers more than senders. They formed three generations of three communicators. In the first generation, three people received firsthand behavioral information about a target group (more stereotypical than counterstereotypical information) and each wrote three notes to the second generation participants, who received all three notes from the first generation and wrote three notes to the third generation participants. Written communications were sent from one generation to the next, but there was no interaction. They found that the attribution of stereotypical traits became more extreme from the first to the second generation though it did not change from the second to the third generation. It is unknown whether the first generation senders' impressions were more polarized due to communication because there was no control; however, communication seems to have affected the receivers' impressions more than the senders' in this study.

Nonetheless, neither Brauer et al.'s (1995) nor Thompson et al.'s (2000) study examined communication processes as joint activities between a sender and a receiver. Brauer et al. did not examine explicitly how people's expressions were grounded by their audiences; Thompson et al.'s Experiment 1 was a one-way communication from one generation to the next without feedback from the latter to the former. Thus, the present study examined how grounding as joint activities promotes essentialism in senders and receivers.

\section{METHOD}

\section{Participants and Design}

Thirty-six undergraduate students ( 3 men, 33 women) at a university in Melbourne took part in the study. They were either native speakers of English or had 
lived in Australia more than 15 years. Two participants were recruited at a time to form a pair. It was ensured that they had no contact prior to the experiment. One in each pair was randomly assigned the role of a sender, who read the information about a group of people; the other took the role of a receiver, who was to form an impression of the group on the basis of the information communicated to him or her through conversation with the sender. Participants were given either positive or negative behaviors as in Study 2 .

The design was a role (sender vs. receiver) x prevalent behavior (positive vs. negative) factorial with the former as a repeated measures factor.

\section{Procedure}

A male experimenter greeted two unacquainted participants when they arrived. He described the experiment as examining how people communicate about a group to another person who has no knowledge about the group. Participants were randomly assigned to the roles of sender and receiver. The receiver was then instructed to start and lead the conversation by asking questions about the group and generally to keep the conversation active. The sender and the receiver were then taken to separate rooms adjacent to the original room. The experimenter gave the sender a list of behaviors purportedly performed by the members of the target group. The list contained the 36 behaviors used in Study 2 in a random order, and the sender was given 5 minutes to read through it and to form impressions about the group, so that he or she could "communicate what you have learned about the group to your communication partner." While the sender read the stimuli, the receiver performed an unrelated task. When the time was up, the sender and receiver were then ushered back to the original room, where they were told to start their conversation. A video camera was visible from the participants, they were told that a conversation would continue for 5 minutes, the instructions were repeated for the receiver to start the conversation by asking questions about the target group, and the experimenter left the room.

After 5 minutes, the experimenter returned to the room, stopped the camera, and handed out a questionnaire in which participants rated the target group on four trait dimensions (kind, unkind, organized, and disorganized) on a 5-point scale $(1=$ not at all, $5=$ very $)$. Participants also responded to the three immutability belief items ( 1 = disagree, 5 = agree $)$.

\section{RESULTS}

\section{Conversational Data}

The videotaped conversations were transcribed. The same coding procedure was followed as in Study 2. The inter-rater reliability was acceptable for grounding $(\kappa=$ $.75)$ as well as for the classification of the statements $(\kappa=.78)$. Disagreements were resolved by discussion. Although we coded for the extent to which receivers expressed agreement or disagreement with the senders' presentations, there was no instance of disagreement; therefore, this was not included in the further analysis. Given the nature of the task--senders had all the information and receivers had none--this is expected. Based on the coding, grounding index was computed as in Study 2. 


\section{Judgment Data}

Again, the absolute value of the difference between the rating of kindness and the rating of unkindness was computed to index the judgment extremity on the kindness dimension; the absolute value of the difference between the rating of organization and that of disorganization was used as the judgment extremity on organization. The extremity score served as the measure of the strength of dispositional attribution. Immutability belief was computed by averaging the three items. Nonetheless, the reliability was relatively low $(\alpha=.57)$, thus requiring a cautious interpretation. There was no significant difference between the senders and receivers on any of the scores, $t<.60$, ns. Their group impressions were analyzed separately.

Sender. An analysis of covariance was conducted on the extremity score with prevalent behavior (positive vs. negative) as a between-subjects factor and dimension (kindness vs. organization) as repeated measures, and grounding as a covariate. As expected, the main effect of grounding was significant, $F(1,15)=9.58, \eta_{p}{ }^{2}$ $=.39, p=.007$. There was also a significant interaction of stimulus and dimension, Wilks's $\Lambda=.73, F(1,15)=5.68, \eta_{p}^{2}=.28, p=.031$. The estimated means showed that judgment extremity was greater on organization than on kindness when the overall stimulus was negative (Means: Kind $=.54$; Organized $=1.18$ ); however, there was no difference between the two for the positive set (Means: Kind = .87; Organized $=.86$ ).

Because there was no dimension $\mathrm{x}$ grounding interaction, Wilks's $\Lambda=.73, F(1$, $15)=2.28, \eta_{p}^{2}=.13, p=.15$, we computed the average of the extremity scores and correlated it with grounding. We computed the correlations of grounding with extremity scores on kindness and organization separately as well because we only found a marginal effect on kindness in Study 2. The results are reported in Table 2. All correlations were in the expected direction and mostly significant; however, the correlation between grounding and kindness was not significant.

An ANCOVA was also conducted on sender's immutability belief with stimulus type as a between-subjects factor and grounding as a covariate. Only the main effect of grounding was significant, $F(1,14)=5.33, \eta_{p}^{2}=.28, p=.037$.

Receiver. Extremity scores on kindness and organization were subjected to an analysis of covariance with prevalent behavior (positive vs. negative) as a betweensubjects factor, dimension as within-subjects factor, and grounding as a covariate. Only the main effect of grounding was significant, $F(1,15)=5.14, p=.039, \eta_{p}{ }^{2}=.26$. Immutability belief was analyzed with an ANCOVA with prevalent behavior as a between-subjects factor and grounding as a covariate. However, none of the effects was significant. Again, comparable correlations were computed (Table 2). All correlations were statistically significant except that receiver immutability belief did not correlate with grounding.

\section{DISCUSSION}

Study 3 showed the relationship between grounding activities and essentialism. The receivers' more elaborate acceptance of the senders' communication encouraged the senders to essentialize the target group, namely, to make stronger disposi- 
tional attributions and to hold stronger beliefs that the dispositions are immutable. Therefore, the senders whose communication was elaborately grounded have felt that the target group possessed an immutable essence. It is interesting to note that for senders, the relationship between grounding and extremity was significant for organization, but not for kindness. This parallels the results in Study 2, where the effect of grounding was clearly significant for organization, but only marginal for kindness. It is difficult to interpret this difference, but may require further research into the difference between the moral dimension related to warmth and coldness (such as kindness) and the ability dimension related to competence and incompetence (such as organization) in future research. By contrast, for receivers, although the more elaborate grounding appears to polarize the receivers' group impressions on both kindness and organization, this did not translate to a stronger belief in the immutability of the group disposition. This suggests that grounding activities do not necessarily result in the receivers' shared reality. It is understandable that the receivers did not feel that their comprehension of the senders' impressions meant their tacit agreement.

The results were generally in line with Brauer et al.'s (1995) findings about group discussion and attitudes. Given the nature of the current task, all grounding activities were based on the senders' expressed opinions about the target: the more the senders expressed their views about the target group, the more grounding activities have occurred, and the greater was the polarization. However, our results went beyond their findings in that not only were group dispositions attributed more strongly, but the attributed dispositions were more strongly believed to be immutable. Nonetheless, the effects of grounding on the receivers' group dispositional attributions somewhat diverged from Brauer et al.'s results; in their study, hearing others' opinions did not affect receivers' attitudes. Still, our results are understandable given the nature of the task. Receivers had only the senders' communications in making judgments about the target group: the more information was grounded about the target group, the stronger were the receivers' dispositional attributions. This may have simply reflected the effect of the amount of information available to the receivers.

This study yielded results somewhat different from Thompson et al.'s Experiment 1 , where they found that receivers' impressions were more polarized than senders'. However, this may be because of the difference in the communication task. Thompson et al.'s receivers received three independent communications from three senders. The fact that multiple senders independently gave similar communications about the target group would surely increase the intersubjective validity of the target impression, just as in Asch's (1956) classical research where the level of conformity increased when the pressure came from three people rather than only two. In the present study, there was only one information source.

\section{GENERAL DISCUSSION}

The results generally supported the hypothesis that communication promotes essentialism through grounding. We argued that two measures would reflect essentialism as a psychological symptom of the feeling that a social category is socially real, namely, attributions of dispositions to a social category and beliefs in their immutability. In Study 1, communicators essentialized more than those who sim- 
TABLE 3. Meta-Analysis of the Effect Sizes $(z)$ in Studies 1 Through 3

\begin{tabular}{lccccc}
\hline Study & $N$ & \multicolumn{2}{c}{ Extremity } & \multicolumn{2}{c}{ Immutability Belief } \\
\hline Study 1 & 92 & 2.78 & $(2.20)$ & 2.26 & \\
Study 2 & 40 & 1.64 & & 2.88 & $(1.75)$ \\
Study 3 & 18 & 2.68 & $\left(3.85^{* * *}\right)$ & $2.75^{*}$ & $\left(3.09^{*}\right)$ \\
Overall z & $3.63^{* *}$ & $(2.55)$ & 1.63 & $(1.08)$ \\
$\chi^{2}$ & 2.81 & $(.28)$ & .44 & $(.58)$ \\
$p$ for $\chi^{2}$ & .25 & $(9)$ & 3 & $(5)$ \\
Fail-safe $N$ & 8 & & & \\
\hline
\end{tabular}

Note. Within parentheses are the relevant numerical values based on measured (rather than manipulated) grounding in study $2 ;{ }^{* * *} p<.0001 ;{ }^{* *} p<.001 ; * p<.01$.

ply memorized information. In Study 2, we manipulated the grounding activities. Extensive grounding strengthened the senders' attribution of one of the dispositions (i.e., organization), but not the other. When measured grounding was used as a predictor, it was shown to correlate with the senders' overall dispositional attribution, but it did not significantly correlate with immutability belief. Instead of the contrived conversations, in Study 3, naive participants acted as senders and receivers. They showed stronger attributions of dispositions to the social category when they engaged in more extensive grounding; however, grounding was associated with the senders' immutability beliefs only, and not with the receivers'.

The overall weight of evidence appears to support the hypothesis; however, we decided to conduct a simple meta-analysis to estimate the effect sizes of the relationships of grounding with dispositional attribution and immutability belief. The F-statistic (and the relevant degree of freedom) computed within the ANOVA or ANCOVA was used to estimate a $z$-valued effect size for each study, and the overall effect size was then estimated by weighting each effect size by the sample size (Judd, Smith, \& Kidder, 1991). We used META (Kenny, 2003) to compute the relevant statistics (Table 3 ). The effect sizes were reasonably homogeneous $\left(\chi^{2}\right.$ statistics were not significant). The overall effect size was highly significant for both dispositional attribution and immutability belief. When converted to correlations, the relation between grounding and dispositional attribution was approximately .31 , and the relation between grounding and immutability belief was .21. We also computed the effect sizes based on the measured grounding, rather than manipulated grounding; the overall effect sizes were again significant for dispositional attribution and immutability belief. The fail-safe $N$, which indicates the number of nil results required to make the overall effect nonsignificant, suggests that the results were reasonably robust.

It is perhaps not too surprising that elaborate grounding strengthens the attribution of underlying dispositions to a social category. Provided that there is already a spontaneous cognitive tendency to make dispositional inferences while just planning to communicate (Hoffmann et al., 1984), elaborate grounding could facilitate their cognitive rehearsal, elaboration, and bolstering along the relevant trait dimension, and this can produce a moderate level of relationship between grounding and dispositional attribution. However, it is intriguing to consider the following possibility. It may be because communicators are usually asked to elaborate along dispositional trait dimensions in typical conversations about individu- 
als and groups that they tend to make spontaneous trait inferences when they are preparing to communicate about them. In other words, it may be the linguistic practice of talking about dispositional trait implications that is responsible for the grounding-polarization relationship.

Nonetheless, it is less obvious how cognitively elaborating on an inferred disposition alone can turn it into an immutable essence. Elaboration would make the inferred disposition more extreme, but why should elaboration make it immutable? We contend that it is the activation of the essence-appearance schema due to its intersubjective verification that turns the inferred disposition into an immutable essence. Thus, our findings add to the growing literature on shared reality by showing that elaborate grounding strengthens immutability beliefs about the attributed dispositions. This aspect of the findings suggests that interpersonal communication, particularly, grounding processes, plays a significant role in the construction of a shared social reality. As we noted earlier, the immutability aspect of essentialism implies that the immutable essence is beyond human intervention and manipulation; it may be believed to be something entrenched in one's shared reality that it cannot be altered. Although this latter effect is only weak, if recurrent and cumulated over time, it may play an important role.

Our theoretical reasoning and empirical data suggest that some conditions need to be met for grounding to result in essentializing. First, senders have ambiguous information, but receivers have no information, about a social category. Second, the receivers should have sufficient epistemic credibility for the senders to be able to act as a partner for social verification. Echterhoff et al.'s (2005) work suggests that the sender and receiver's shared group membership satisfies this condition. It is the ambiguity of the information that motivates the senders to seek intersubjective verification about the social category, and it is the epistemic authority of the senders that prevent receivers from voicing disagreement. The senders take the absence of an explicit dissent as a tacit agreement, and this result in their assumption that there is a shared reality because the receiver is seen by the sender to have sufficient epistemic credibility. However, the grounding-essentializing process does not apply to receivers; the fact that they do not express disagreements does not mean that they agree, and they presumably do not activate the essenceappearance schema.

This implies that when both communicators already have some information by observing members of a social category, mere grounding is unlikely to be sufficient for the essentialization of the social category. In this instance, the sender and the receiver are equal in their epistemic authority--unless one has a special expertise or other status characteristic--and neither may be willing to take the absence of an explicit disagreement as sufficient evidence for intersubjective verification. Here, an explicit agreement about each other's perceptions, beliefs, and feelings may be required to establish the shared reality of a social category, and to essentialize it.

Second, the grounding-essentializing process applies only to social categories because the essence-appearance schema is less likely to be applied to other types of social groups based on shared goals and tasks (e.g., juries, committees, boards of directors). When group members' behaviors are used as a basis for inferring their shared goals (Ip et al., 2006), these goals are less likely to be seen as immutable because goals are humanly constructed psychological entities. This is not to say that goal-based groups can never be essentialized--witness essentialization of terrorist groups for instance--but they are less likely to be. 
All in all, the present research showed that there exists a circumstance in which interpersonal grounding processes, and resultant establishment of shared reality, play a significant role for the communicative construction of the social reality of a social category. It remains to be seen how far and how strong this phenomenon may extend in our everyday life.

\section{REFERENCES}

Allport, G. W. (1954). The nature of prejudice. Cambridge, MA: Addison-Wesley.

Anderson, N. H. (1981). Foundations of information integration theory. NY: Academic.

Asch, S. E. (1952). Social psychology. Englewood Cliffs, NJ: Prentice-Hall.

Asch, S. (1956). Studies of independence and conformity: A minority of one against a unanimous majority. Psychological Monographs, 70.

Baron, R. M., \& Kenny, D. A. (1986). The moderator-mediator variable distinction in social psychological research: Conceptual, strategic, and statistical considerations. Journal of Personality and Social Psychology, 51, 1173-1182.

Bastian, B., \& Haslam, N. (2006). Psychological essentialism and stereotype endorsement. Journal of Experimental Social Psychology, 42, 228-235.

Bavelas, J. B., Coates, L., \& Johnson, T. (2000). Listeners as co-narrators. Journal of Personality and Social Psychology, 79, 941-952.

Berger, P., \& Luckmann, T. (1967). The social construction of reality. London, UK: Penguin Books.

Brauer, M., Judd, C. M., \& Gliner, M. D. (1995). The effects of repeated expressions on attitude polarization during group discussions. Journal of Personality and Social psychology, 68, 1014-1029.

Brauer, M., Judd, C. M., \& Jacquelin, V. (2001). The communication of social stereotypes: The effects of group discussion and information distribution on stereotypic appraisals. Journal of Personality and Social Psychology, 81, 463-475.

Brewer, M. B., Weber, J. G., \& Carini, B. (1995). Person memory in intergroup contexts: Categorization versus individuation. Journal of Personality and Social Psycholo$g y, 69,29-40$.
Campbell, D. T. (1958). Common fate, similarity, and other indices of the status of aggregates of persons as social entities. Behavioral Science, 3, 14-25.

Chiu, C.-Y., Hong, Y.-Y., \& Dweck, C. S. (1997). Lay dispositionism and implicit theories of personality. Journal of Personality and Social Psychology, 73, 19-30.

Clark, H. H. (1996). Using language. Cambridge, UK: Cambridge University Press.

Dasgupta, N., Banaji, M. R., \& Abelson, R. P. (1999). Group entitativity and group perception: Associations between physical features and psychological judgment. Journal of Personality and Social Psychology, 77, 991-1003.

Durkheim, E. (1982). The rules of sociological method. S. Lukes (Ed.) \& W. D. Halls (Trans.). London, UK: Macmillan.

Dweck, C. S. (1999). Self-theories: Their role in motivation, personality, and development. Philadelphia: Psychology Press.

Dweck, C. S., Chiu, C.-Y., \& Hong, Y.-Y. (1995). Implicit theories and their role in judgments and reactions: A world from two perspectives. Psychological Inquiry, 6, 267-285.

Echterhoff, G., Higgins, E. T., \& Groll, S. (2005). Audience-tuning effects on memory: The role of shared reality. Journal of Personality and Social Psychology, 89, 257-276.

Echterhoff, G., Higgins, E. T., Kopietz, R., \& Groll, S. (2008). How communication goals determine when audience tuning biases memory. Journal of Experimental Psychology: General, 137, 3-21.

Festinger, L. (1950). Informal social communication. Psychological Review, 57, 271-282.

Gelman, S. A. (2004). Psychological essentialism in children. Trends in Cognitive Science, 8, 404-409. 
Giddens, A. (1993). New rules of sociological method. Stanford, CA: Stanford University Press.

Guerin, B., \& Innes, J. M. (1989). Cognitive tuning sets: Anticipating the consequence of communication. Current Psychology: Research \& Reviews, 8, 234-249.

Hamilton, D. L., \& Sherman, S. J. (1996). Perceiving persons and groups. Psychological Review, 103, 336-355.

Hardin, C. D., \& Higgins, E. T. (1996). Shared reality: How social verification makes the subjective objective. In R. M. Sorrentino \& E. T. Higgins (Eds.), Handbook of motivation and cognition (Vol. 3, pp. 28-84). New York: Guilford.

Harvey, J. H., Harkins, S. G., \& Kagehiro, D. K. (1976). Cognitive tuning and the attribution of causality. Journal of Personality and Social Psychology, 34, 708-715.

Haslam, N. O., Rothschild, L., \& Ernst, D. (2000). Essentialist beliefs about social categories. British Journal of Social Psychology, 39, 113-127.

Haussmann, L. R. M., Levine, J. M., \& Higgins, E. T. (2008). Communication and group perception: Extending the "Saying is Believing" effect. Group Processes and Intergroup Relations, 11, 539-554.

Higgins, E. T. (1992). Achieving "shared reality" in the communication game: A social action that creates meaning. Journal of Language and Social Psychology, 11, 107-125.

Higgins, E. T., \& Rholes, W. S. (1978). "Saying is believing": Effects of message modification on memory and liking for the person described. Journal of Experimental Social Psychology, 14, 363-378.

Hoffmann, C., Mischel, W., \& Baer, J. S. (1984). Language and person cognition: Effects of communicative set on trait attribution. Journal of Personality and Social Psychology, 46, 1029-1043.

Ip, G. W.-M., Chiu, C.-Y., \& Wan, C. (2006). Birds of a feather and birds flocking together: Physical versus behavioral cues may lead to trait- versus goal-based goal perception. Journal of Personality and Social Psychology, 90, 368-381.

Judd, C. M., Smith, E. R., \& Kidder, L. H. (1991). Research methods in social relations (6th ed.). Orlando, FL: Harcourt Brace Javanovich.
Kashima, Y. (2004). Culture, communication, and entitativity: A social psychological investigation of social reality. In $\mathrm{V}$. Yzerbyt, C. Judd, \& O. Corneille (Eds.), The psychology of group perception (pp. 257-273). Hove, UK: Psychology Press.

Kashima, Y., Kashima, E., Chiu, C., Farsides, T., Gelfand, M., Hong, Y., et al. (2005). Culture, essentialism, and agency: Are individuals universally believed to be more real entities than groups? European Journal of Social Psychology, 35, 147-169.

Kashima, Y., Klein, O., \& Clark, A. E. (2007). Grounding: sharing information in social interaction. In K. Fiedler (Ed.), Social communication (pp. 27-77). New York: Psychology Press.

Kashima, Y., Woolcock, J., \& Kashima, E. S. (2000). Group impressions as dynamic configurations: The tensor product model of group impression formation and change. Psychological Review, 107, 914-942.

Kenny, D. A. (2003). Meta-analysis: Easy to answer. Unpublished manuscript. University of Connecticut (downloaded from http:/ /davidkenny.net/meta.htm).

Levy, S. R., Stroessner, S. J., \& Dweck, C. S. (1998). Stereotype formation and endorsement: The role of implicit theories. Journal of Personality and Social Psycholo$g y, 74,1421-1436$.

Lickel, B., Hamilton, D. L., Wieczorkowska, G., Lewis, A., Sherman, S. J., \& Uhles, A. N. (2000). Varieties of groups and the perception of group entitativity. Journal of Personality and Social Psychology, 78, 223-246.

Medin, D. L., \& Ortony, A. (1989). Psychological essentialism. In S. Vosniadou \& A. Ortony (Eds.), Similarity and analogical reasoning (pp. 179-195). Cambridge, UK: Cambridge University Press.

Moscovici, S. (1976). Social influence and social change. New York: Academic.

Park, B., \& Judd, C. M. (1990). Measures and models of perceived group variability. Journal of Personality and Social Psychology, 59, 173-191.

Rommetveit, R. (1974). On message structure. New York: Wiley.

Rothbart, M., \& Taylor, M. (1992). Category labels and social reality: Do we view social categories as natural kinds? In G. R. Semin \& K. Fiedler (Eds.), Language, 
interaction and social cognition (pp. 11-36). London, UK: Sage.

Searle, J. R. (1995). The construction of social reality. London, UK: Penguin Books.

Sherif, M. (1936). The psychology of social norms. New York: Harper.

Thompson, M. C., Judd, C. M., \& Park, B. (2000). The consequences of communicating social stereotypes. Journal of Experimental Social Psychology, 36, 567-599.

Yzerbyt, V., Judd, C. M., \& Corneille, O. (Eds.). (2004). The psychology of group perception: Perceived variability, entitativity, and essentialism. New York: Psychology Press.

Yzerbyt, V., Rocher, S., \& Schadron, G. (1997). Stereotypes as explanations: A subjective essentialistic view of group perception. In R. Spears, P. J. Oakes, N. Ellermers, \& S. A. Haslam (Eds.), The social psychology of stereotyping and group life (pp. 20-50). Oxford, UK: Blackwell.

Yzerbyt, V. Y., Rogier, A., \& Fiske, S. T. (1998). Group entitativity and social attribution: On translating situational constraints into stereotypes. Personality and Social Psychology Bulletin, 24, 1089-1103.

Zajonc, R. B. (1960). The process of cognitive tuning in communication. Journal of $A b$ normal and Social Psychology, 61, 159-167. 